\title{
Apolipoprotein J Measurement
}

National Cancer Institute

\section{Source}

National Cancer Institute. Apolipoprotein/Measurement. NCI Thesaurus. Code C100428.

The determination of the amount of apolipoprotein J present in a sample. 